\title{
Comparison of the effects of intravenous and oral montelukast on airway function: a double blind, placebo controlled, three period, crossover study in asthmatic patients
}

R J Dockhorn, R A Baumgartner, J A Leff, M Noonan, K Vandormael, W Stricker, D E Weinland, T F Reiss

\begin{abstract}
Background-Montelukast, a leukotriene receptor antagonist, improves parameters of asthma control including forced expiratory volume in one second $\left(\mathrm{FEV}_{1}\right)$ when given orally to patients aged six years or older. This study was undertaken to compare the effect on $\mathrm{FEV}_{1}$ of intravenous and oral montelukast and placebo during the 24 hour period following administration. one asthmatic $\left(\mathrm{FEV}_{1} 40-80 \%\right.$ predicted and $\geqslant 15 \%$ improvement after inhaled $\beta$ agonist) were enrolled in a double blind, single dose, three period, crossover study to receive intravenous montelukast $(7 \mathrm{mg})$, oral montelukast $(10 \mathrm{mg})$, or placebo in a randomised fashion. The primary end point was area under the curve (AUC) $)_{0-24 \mathrm{~h}}$ of the percentage change from baseline in $\mathrm{FEV}_{1}$. Additional end points were maximum percentage change in $\mathrm{FEV}_{1}$ and percentage change at different time points.

Results-Compared with placebo, intravenous and oral montelukast significantly increased the $\mathrm{AUC}_{0-24 \mathrm{~h}}$ (means of $20.70 \%$, $15.72 \%$, and $7.75 \%$ for intravenous, oral and placebo, respectively; no statistical difference between intravenous and oral). The difference in least square means from placebo for intravenous montelukast was $13.27 \%$ (95\% CI 7.07 to 19.46$)$, $p<0.001$ and for oral montelukast was $7.44 \%$ (95\% CI 1.20 to 13.68$), p=0.020$. The maximum percentage change in $\mathrm{FEV}_{1}$ was not significantly different for intravenous and oral montelukast (difference in least square means $6.78 \%(95 \%$ CI -0.59 to 14.15$), p=$ $0.071)$. The mean percentage change in FEV $_{1}$ for intravenous montelukast was greater than for oral montelukast within the first hour $(15.02 \%$ vs $4.67 \%$ at $15 \mathrm{~min}$, $p \leqslant 0.001 ; 18.43 \%$ vs $12.90 \%$ at one hour, $\mathbf{p}<\mathbf{0 . 0 0 1}$ for intravenous and oral montelukast, respectively (placebo $3.05 \%$ at 15 minutes, $7.33 \%$ at one hour). Intravenous and oral montelukast were similar
\end{abstract}

Merck Research, MSD, Brussels, Belgium

K Vandormael

Merck Research

Laboratories, Rahway,

New Jersey, USA

R A Baumgartner

J A Leff

D E Weinland

T F Reiss

International Medical and Technical

Consultants Inc,

Lenexa, Kansas, USA

R J Dockhorn

Allergy Associates, PC Research Center, Portland, Oregon, USA

M Noonan

Clinical Research of the Ozarks Inc, Columbia, Missouri, USA

W Stricker

Correspondence to: Dr T F Reiss, Merck Research Laboratories, RY 32-648, Rahway, New Jersey 07065-1900, USA

Received 24 March 1999 Returned to authors 24 May 1999

Revised version received

10 June 1999

Accepted for publication

13 July 1999 to placebo in the frequency of adverse events.

Conclusions-The onset of action for intravenous montelukast was faster than for oral montelukast and the improvement in airway function lasted over the 24 hour observation period for both treatments. Although not well understood, there was a trend toward a greater improvement in FEV $_{1}$ with intravenous than with oral montelukast. These findings suggest that leukotriene receptor antagonists should be investigated as a treatment for acute severe asthma.
(Thorax 2000;55:260-265)

Keywords: asthma; leukotriene receptor antagonist; montelukast

The incidence of asthma has increased substantially in many countries during the last two decades in both children and adults. ${ }^{1}$ In addition, the number of patients presenting to emergency room departments with severe acute asthma exacerbations has also increased in some countries. ${ }^{2}$ The reasons for this increase remain speculative. Despite these changes in the epidemiology of acute asthma, drug treatment for acute severe asthma has changed little over the last two decades, consisting primarily of bronchodilators, corticosteroids, and oxygen.

Leukotrienes, products of inflammatory cells such as eosinophils and mast cells, are released during acute asthma attacks ${ }^{4}$ and have increasingly become recognised as inflammatory mediators that play a significant role in the pathophysiology of asthma. ${ }^{5-8}$ Recently, montelukast, an orally active, potent and specific cysteinyl leukotriene receptor antagonist, has been shown to improve asthma control in more. ${ }^{910}$ In addition, the improvement in forced expiratory volume in one second $\left(\mathrm{FEV}_{1}\right)$ observed with oral montelukast appears to be additive to that of $\beta$ agonists and to occur within a few hours after administration. ${ }^{10}$ patients with chronic asthma aged six years or 
Table 1 Baseline characteristics of patients

\begin{tabular}{lll}
\hline Characteristics & Mean (SD) & Range \\
\hline Age (years) & & \\
$\quad$ All patients (n=51) & $29.8(11.2)$ & $15.0-56.0$ \\
Men (n=29) & $28.9(12.0)$ & $15.0-56.0$ \\
$\quad$ Women (n=22) & $31.0(10.3)$ & $18.0-51.0$ \\
Weight $(\mathrm{kg})^{\star}$ & $78.5(15.5)$ & $52.6-124.2$ \\
Height $(\mathrm{cm})^{\star}$ & $171.8(8.4)$ & $154.9-190.5$ \\
Duration of asthma (years) & $19.2(11.7)$ & $2.3-50.4$ \\
FEV $_{1}(1)^{\star}$ & $2.5(0.6)$ & $1.3-3.8$ \\
FEV $_{1}(\%$ of predicted) & $63.8(11.2)$ & $42.8-80.2$ \\
\hline
\end{tabular}

${ }^{\star}$ Measurements taken at prestudy visit.

In this study we have investigated the speed of onset, duration of action, and the magnitude of effect of intravenous versus oral montelukast on airway function in chronic asthmatic patients.

\section{Methods}

PATIENTS

Fifty one patients (22 women) with at least a one year history of chronic asthma, an $\mathrm{FEV}_{1}$ of $40-80 \%$ predicted, and with a $\geqslant 15 \%$ improvement in $\mathrm{FEV}_{1}$ (absolute value) after inhaled $\beta$ agonist were enrolled (table 1). Patients were eligible to participate if they were currently non-smokers (smoking history $\leqslant 7$ pack years) and had not taken oral, intravenous, or intramuscular corticosteroids during the month prior to the start of the study (inhaled corticosteroids were allowed in up to $25 \%$ of patients as long as the dosing had been stable for two weeks prior to and during the study). Those taking long acting antihistamines within two weeks of the first prestudy visit, or theophylline, oral or long acting inhaled $\beta$ agonists, cromolyn sodium or nedocromil, or inhaled anticholinergics within one week, or short acting antihistamines during the 48 hours before the visit were excluded. The study was approved by local ethics committees and the patients gave written informed consent.

\section{STUDY DESIGN}

This was a multicentre, double blind, randomised, placebo controlled, three period crossover study.

The study was composed of a prestudy visit (where inclusion/exclusion criteria were determined) and three efficacy periods (periods I-III). Patients were allocated randomly to receive a single dose of intravenous montelukast $(7 \mathrm{mg})$, oral montelukast $(10 \mathrm{mg}$ ), or placebo during each of the three periods after withholding inhaled $\beta$ agonist for six hours.

Study medication was administered the same time of morning ( \pm one hour) on each treatment day; thereafter, patients were observed for 24 hours to document the effect on $\mathrm{FEV}_{1}$. At least four (but no more than 14) days elapsed between treatment periods. Physical examinations, vital signs, local intravenous site evaluation, spirometric measurements, and laboratory safety tests were performed.

Spirometric measurements (PuritanBennett PB 100) were conducted 30 minutes and five minutes before administration of the study drug and $0.25,0.5,1,2,4,8,12,16$, and 24 hours afterwards in accordance with the reproducibility and acceptability criteria of the
American Thoracic Society. ${ }^{11}$ If the $\mathrm{FEV}_{1}$ was less than $40 \%$ predicted or more than $80 \%$ predicted prior to drug administration the patient was treated with inhaled salbutamol and rescheduled for administration of the study drug on another day. If after drug administration a patient's $\mathrm{FEV}_{1}$ fell by more than $25 \%$ of its initial value or fell below $40 \%$ of the predicted normal value, or if the investigator or patient felt it was indicated, the patient was treated with inhaled albuterol.

An intravenous catheter was inserted for collection of pretreatment blood for laboratory safety tests. After blood collection the intravenous site was converted to a heparin lock and used for administration of study drug with vehicle (dextrose 3.3\%/sodium chloride $0.3 \%)$.

DOSE SELECTION AND ADMINISTRATION

A preliminary study ${ }^{12}$ indicated that the plasma concentration-time profile of intravenous montelukast was proportional to the dose over the range of $3-18 \mathrm{mg}$. In an additional study (unpublished) an intravenous dose of $7 \mathrm{mg}$ was identified as the dose resulting in a comparable area under the plasma concentration-time curve (AUC) as that obtained with $10 \mathrm{mg}$ oral montelukast - the minimal oral dose demonstrating maximal clinical efficacy in patients with chronic asthma. ${ }^{13-15}$

The intravenous dose of montelukast $(7 \mathrm{mg}$, $0.23 \mathrm{mg} / \mathrm{ml}$ ) or matching placebo was given as a manual bolus in a syringe (containing $30 \mathrm{ml}$ of drug or placebo) over two minutes. The prepared solution of drug was light sensitive so the syringe was protected by wrapping in aluminum foil. At the end of the drug administration the catheter was flushed with $2-3 \mathrm{ml}$ of vehicle. The study medication tablet (montelukast $10 \mathrm{mg}$ or placebo) was administered with $150 \mathrm{ml}$ water.

The patients were observed in the unit for 24 hours after administration of the study drug. Vital signs were measured frequently (patients sat or reclined for at least five minutes prior to measurements). All patients had laboratory safety tests (blood at prestudy visit, 30 minutes before and 24 hours after drug administration; urine at prestudy visit, 60 minutes before and 24 hours after administration of study drug). Adverse effects and vital signs were recorded at each visit.

EVALUATIONS AND STATISTICAL ANALYSIS

Data from all patients were included in the analysis of efficacy and safety (intention to treat approach).

The primary end point was $\mathrm{AUC}_{0-24 \mathrm{~h}}$ (area under the $\mathrm{FEV}_{1}$ percentage change from baseline/time curve, standardised for time of follow up, see below). Secondary end points were maximum percentage change in $\mathrm{FEV}_{1}$ from baseline and percentage change from baseline in $\mathrm{FEV}_{1}$ at each measured time point following treatment. The baseline for all end points was the average of the two pretreatment values 30 and five minutes before each period. Post hoc analysis included evaluating the proportion of patients requiring rescue medi- 
Table 2 Baseline FEV by period and treatment

\begin{tabular}{lll}
\hline & No. & Mean (SD) \\
\hline FEV $_{1}(1)$ & & \\
By period $_{\text {I }}^{\star}$ & 51 & $2.42(0.64)$ \\
II & 50 & $2.50(0.68)$ \\
III & 50 & $2.48(0.69)$ \\
By treatment & & \\
$\quad$ IV montelukast & 50 & $2.42(0.64)$ \\
$\quad$ Oral montelukast & 51 & $2.48(0.72)$ \\
$\quad$ Placebo & 50 & $2.50(0.64)$ \\
FEV & \\
By period of predicted) & & \\
I & 51 & $62.23(11.97)$ \\
II & 50 & $64.20(11.53)$ \\
III & 50 & $63.94(12.33)$ \\
By treatment & & \\
IV montelukast & 50 & $62.28(11.55)$ \\
$\quad$ Oral montelukast & 51 & $63.66(12.82)$ \\
Placebo & 50 & $64.40(11.41)$ \\
\hline
\end{tabular}

${ }^{\star}$ One patient withdrew after period I (see Results section).

cation during the 24 hour period following administration of the study treatment.

$\mathrm{AUC}_{0-24 \mathrm{~h}}$ was calculated as the area under the curve of percentage change in $\mathrm{FEV}_{1}$ from baseline versus time. The AUC was standardised for time of follow up by dividing by the number of hours that the patient had $\mathrm{FEV}_{1}$ measurements performed.

The maximum percentage change in $\mathrm{FEV}_{1}$ from baseline over time was defined as the maximum value during each 24 hour treatment period. The percentage change from baseline in $\mathrm{FEV}_{1}$ at different time points following treatment was calculated at each postrandomised time point after drug administration $(0.25,0.5,1,2,4,8,12,16$, and 24 hours). Missing values in the treatment period were imputed by carrying forward the preceding $\mathrm{FEV}_{1}$ value through all subsequent missing time points in the same period. For patients

Table 3 Area under the curve of percentage change from baseline in FEV standardised for time of follow up $\left(A U C_{0-24}\right)$

\begin{tabular}{llll}
\hline Treatment & Mean (\% change) & $95 \%$ CI for mean & \\
\hline IV montelukast & 20.70 & $(14.43$ to 26.97$)$ & \\
Oral montelukast & 15.72 & $(8.59$ to 22.85$)$ & \\
Placebo & 7.75 & $(1.76$ to 13.75$)$ & \\
Comparison between treatments & Difference in LS & $95 \%$ CI for difference in & p value \\
& means & LS means & \\
IV montelukast vs placebo & 13.27 & $(7.07$ to 19.46$)$ & $<0.001$ \\
Oral montelukast vs placebo & 7.44 & $(1.20$ to 13.68$)$ & 0.020 \\
IV montelukast vs oral montelukast & 5.82 & $(-0.41$ to 12.06$)$ & 0.067 \\
\hline
\end{tabular}

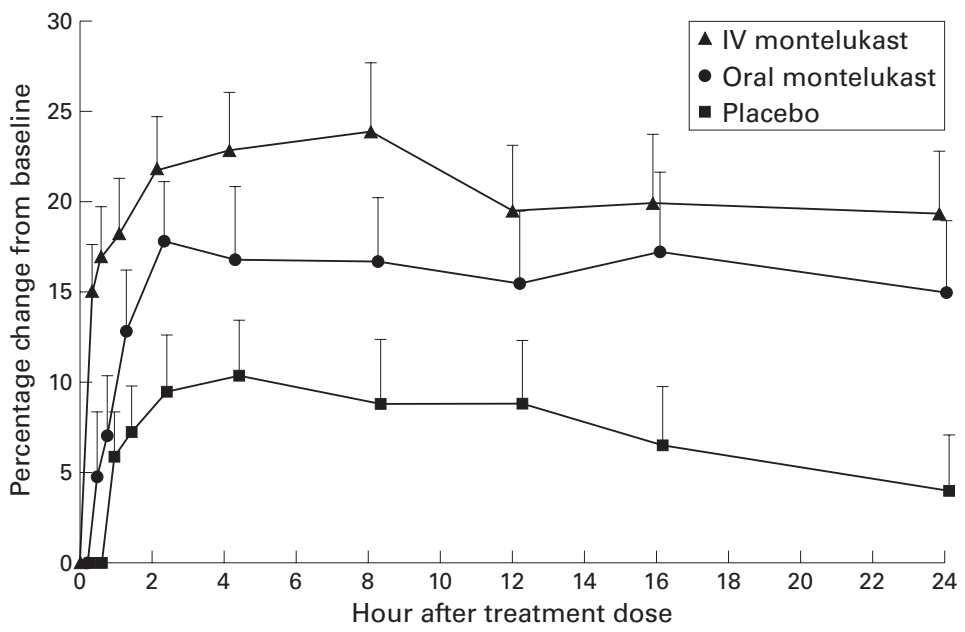

Figure 1 Percentage change from baseline in FEV over the 24 hours following treatment. who needed rescue medication the last recorded $\mathrm{FEV}_{1}$ value before administration of rescue medication was carried forward through all subsequent time points in that treatment period.

The study was analysed using an ANOVA model including factors for study centre, patient (within centre), period, and treatment. The difference between treatments was estimated by the difference in least square means and the associated $95 \%$ confidence interval (CI).

The effect of first order carryover was tested at a significance level of $\alpha=0.10$ and was found to be not significant and was therefore subsequently removed from the model. The "treatment by centre" interaction was assessed at the level of $\alpha=0.10$ and was found to be not qualitatively significant.

The normality assumption of the ANOVA model was assessed by the Shapiro-Wilk statistic. Plots of residuals versus predicted values were also used to examine the assumption of variance homogeneity and no evidence of nonnormal distribution was found.

There are two main comparisons of interest in this study. The first is the placebo comparison-that is, between intravenous montelukast and placebo-and the second is the active treatment comparison-that is, between intravenous and oral montelukast. These two comparisons were prespecified as separate hypotheses of equal interest so no adjustment for multiplicity was necessary.

With 48 completing patients there was a $90 \%$ power to detect a $6.5 \%$ point difference in $\mathrm{FEV}_{1}\left(\mathrm{AUC}_{0-24 \mathrm{~h}}\right.$ in percentage change from baseline) between the active treatment groups assuming a significance level of 0.05 and within-patient variability of $9.7 \%$ as observed in a previous study. ${ }^{12}$

\section{Results}

Fifty one patients were randomised and 50 patients completed the study. One patient withdrew after treatment in period I. This patient developed a poison ivy rash and declined to continue in the study (the patient had been randomised to receive oral montelukast). Tables 1 and 2 list baseline characteristics. Four $(8 \%)$ patients used concomitant inhaled corticosteroids throughout the trial. Predosing baseline $\mathrm{FEV}_{1}$ values did not differ among the treatments or periods (table 2).

$\mathrm{AUC}_{0-24 \mathrm{~h}}$

The mean $\mathrm{AUC}_{0-24 \mathrm{~h}}$ values following treatment are shown in table 3 . The between group differences for least square (LS) means $\mathrm{AUC}_{0-24 \mathrm{~h}}$ were significant for intravenous $(\mathrm{p}<0.001)$ and oral montelukast $(p=0.020)$ compared with placebo. The difference between intravenous and oral montelukast favoured the intravenous form but did not reach statistical significance $(p=0.067)$. The percentage change from baseline in $\mathrm{FEV}_{1}$ over the 24 hours following treatment is shown in fig 1 . 


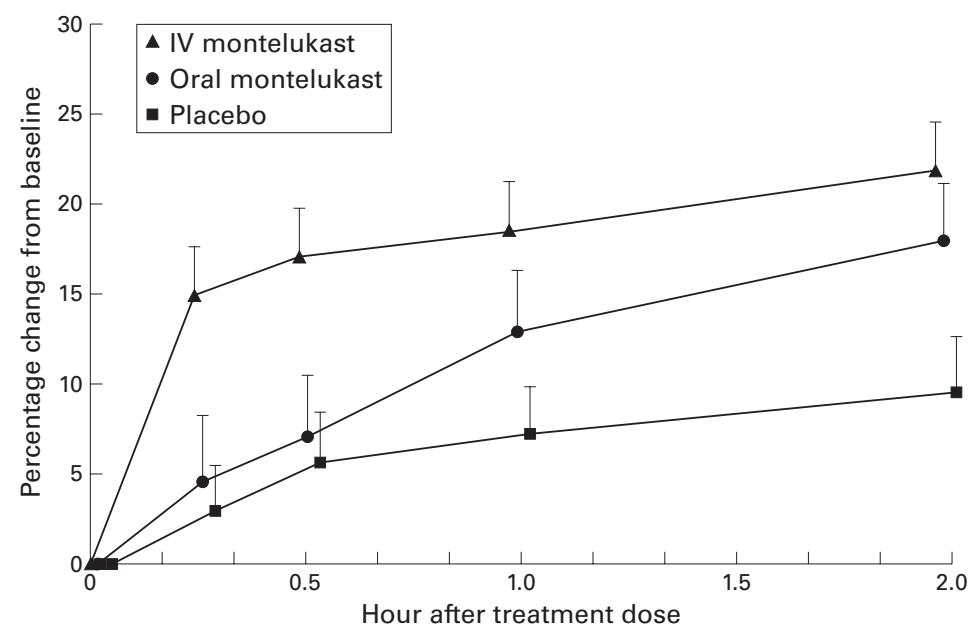

Figure 2 Mean percentage change from baseline in $\mathrm{FEV}$, over two hours after treatment.

MAXIMUM PERCENTAGE CHANGE IN FEV 1 FROM BASELINE

The mean maximum percentage increases in $\mathrm{FEV}_{1}$ from baseline over the 24 hour period were $33.57 \%$ (95\% CI 25.92 to 41.21$)$, $27.19 \%$ (95\% CI 19.32 to 35.06$)$, and $20.33 \%$ (95\% CI 14.24 to 26.42) for intravenous montelukast, oral montelukast, and placebo, respectively. The between group difference for LS means maximum percentage change from baseline in $\mathrm{FEV}_{1}$ was significant for intravenous montelukast $(13.56 \%, \mathrm{p}<0.001)$ compared with placebo but did not reach statistical significance for oral montelukast compared with placebo or for intravenous versus oral montelukast $(6.78 \%, \mathrm{p}=0.071$ for both).

PERCENTAGE CHANGE IN FEV 1 FROM BASELINE AT DIFFERENT TIME POINTS AFTER TREATMENT

Those receiving intravenous montelukast had a significantly better response (increase in $\mathrm{FEV}_{1}$ ) than the placebo group beginning 15 minutes after treatment $(\mathrm{p}<0.001$; figs 1 and 2$)$. The increase in airway function was sustained over the entire 24 hour period $(p \leqslant 0.004)$. The mean percentage change from baseline in $\mathrm{FEV}_{1}$ was significantly higher at the earlier time points (15 minutes to one hour) for intravenous than for oral montelukast. The difference between the two treatments decreased over time and was not significant at $2,4,8,12$, 16, and 24 hours after drug administration $(p>0.05)$. A plot of the mean percentage changes from baseline in $\mathrm{FEV}_{1}$ over two hours is shown in fig 2 .

RESCUE MEDICATION WITH $\beta$ AGONIST

FOLLOWING TREATMENT

Nine, 12, and 15 patients required inhaled short acting $\beta$ agonists for intravenous montelukast, oral montelukast, and placebo, respectively. The difference in proportion approached statistical significance $(\mathrm{p}=0.055)$.

\section{SAFETY RESULTS}

Adverse experiences were similar in frequency in the three treatment groups. The most frequently reported adverse events included headaches, which occurred in three patients $(6 \%)$ on placebo, four $(7.8 \%)$ on oral montelukast, and one $(2 \%)$ on intravenous montelukast, and influenza which occurred in two patients $(4 \%)$ while taking placebo. Specifically, there were no locally reported adverse events relating to the intravenous administration of montelukast.

\section{Discussion}

This study was designed to compare the effect of a single dose of intravenous montelukast (7 mg), oral montelukast $(10 \mathrm{mg})$, and placebo on $\mathrm{FEV}_{1}$ in patients with chronic asthma. To our knowledge this study is the only direct comparison of intravenous and oral formulations of a cysteinyl leukotriene receptor antagonist.

When administered as a two minute bolus intravenous montelukast produced a significant improvement in $\mathrm{FEV}_{1}$ compared with placebo. This improvement was evident when considered as $\mathrm{AUC}_{0-24 \mathrm{~h}}$ for $\mathrm{FEV}_{1}$ after treatment, maximal increase in $\mathrm{FEV}_{1}$ after treatment, or comparisons at each individual time point.

The improvement in $\mathrm{FEV}_{1}$ with intravenous montelukast was noted at the earliest time point measured (15 minutes), indicating a rapid onset of action. Moreover, it was long lasting, occurring at least up to 24 hours after dosing, and clinically important as there were fewer $\beta$ agonist rescues required during the 24 hour period following treatment with intravenous montelukast $(n=9)$ than with placebo ( $n=15$ ). Like intravenous montelukast, oral montelukast also caused significant improvement in pulmonary function compared with placebo (as measured by $\mathrm{AUC}_{0-24}$ in percentage change from baseline $\mathrm{FEV}_{1}$ ). The onset of action for intravenous montelukast was faster than for the oral formulation.

Not surprisingly, intravenous administration also caused maximal airway relaxation (over an observation period of 24 hours or less) to occur more rapidly than with oral formulations. ${ }^{16}$ While there was no statistically significant difference in the $\mathrm{AUC}_{0-24} \mathrm{~h}$ and mean maximal improvement in $\mathrm{FEV}_{1}$, the mean effect of the intravenous drug was numerically larger than the oral drug, despite the fact that both formulation doses caused the same single dose AUC (timeconcentration profile). ${ }^{12}$ While it is true that peak plasma concentrations are greater with intravenous than with oral montelukast, a dose related response in $\mathrm{FEV}_{1}$ has not been seen with doses of oral montelukast above $10 \mathrm{mg}$. A comparison of between study effects with other antileukotriene agents has suggested similar findings. It is possible that the administration of montelukast intravenously might have more favourable interaction kinetics with the cysteinyl leukotriene receptor. Further pharmacokinetic and pharmoacodynamic studies should address these issues.

Previous clinical studies with intravenously administered cysteinyl leukotriene receptor antagonists have been consistent in demon- 
strating a rapid improvement in airway obstruction, usually within minutes of administration. For example, MK-0679 produced improved airflow within 15 minutes (the first post-administration time point measured) with the peak effect occurring within approximately 30 minutes, ${ }^{17}$ and MK-571 demonstrated the ability to protect against exercise induced bronchoconstriction 20 minutes after intravenous administration. ${ }^{18}$ In addition, many studies have demonstrated additive effects of leukotriene receptor antagonists and inhaled $\beta$ agonists in causing airway relaxation. ${ }^{19-21}$

Intravenous montelukast was found to be generally safe and well tolerated. Adverse experiences were few and transient, with no apparent differences between treatments. No patient discontinued the study because of a clinical or laboratory adverse experience and there were no serious adverse experiences noted. Specifically, no clinically significant intravenous site irritation was observed.

A rapidly acting agent which is additive to inhaled $\beta$ agonists may be particularly useful in the treatment of acute asthma. In 1995 there were an estimated 1867000 emergency department visits for asthma in the US alone. Since then the number of emergency department visits has increased at an $8.4 \%$ compounded annual growth rate from 1992 through 1995. Because patients with asthma treated in the emergency department incur significantly lower costs than those admitted to the hospital, and those who fail to respond to the emergency department treatment and require subsequent admission to the hospital constitute the least cost efficient subset, ${ }^{22}$ emergency room physicians are under pressure to determine as quickly as possible whether a patient is to be discharged or admitted. Furthermore, the US Public Health Service has made decreasing the need for inpatient treatment of asthma a national priority. ${ }^{23}$ In such a milieu, quick acting medications are essential.

In the setting of an acute asthma attack, up to one third of patients may not respond to a nebulised $\beta$ agonist. ${ }^{24}$ In addition, anticholinergic agents add little to the effects of a $\beta$ agonist, ${ }^{24}{ }^{25}$ nor do they facilitate recovery in patients whose immediate response to sympathomimetics is impaired. ${ }^{26}$ Likewise, adding methylxanthines to $\beta$ agonists does not result in increased therapeutic efficacy. ${ }^{27}{ }^{28}$ Although there are data to suggest that, in the acute setting, systemic corticosteroids should be administered as soon as possible, ${ }^{29}$ there is also evidence that treatment with parenteral corticosteroids has little beneficial effect during the first hour of administration. ${ }^{30}$ Intravenous or, potentially, oral leukotriene receptor antagonists such as montelukast with a short onset of action and demonstrated additivity to $\beta$ agonists and corticosteroids (Laviolette $\mathrm{M}$, et al, submitted for publication) may have a significant impact in this setting. A study of montelukast in patients with acute asthma may be warranted.
The results of this study indicate that the intravenous formulation of montelukast has an onset of action as fast as 15 minutes after administration with a trend towards greater efficacy even though the plasma AUC levels were similar to oral montelukast. Since intravenous leukotriene receptor antagonists have a rapid and sustained effect on the airways, they might be particularly useful in the treatment of acute asthma.

The authors wish to thank S Schon for her editorial assistance.

Source of funding: Merck Research Laboratories

1 Woolcock AJ, Peat JK. Evidence for the increase in asthma worldwide. In: The rising trends in asthma. Ciba Foundation Worldwide. In: The rising trends in asthma. Ciba Foundation Symposium $122-39$.

2 Kardon EM. Acute asthma. Emerg Med Clin North Am 1996;14:93-114.

3 Lipworth BJ. Treatment of acute asthma. Lancet 1997; 350(Suppl II): $18-23$

4 Drazen JM, O'Brien J, Sparrow D, et al. Recovery of leukotriene E4 from the urine of patients with airway obstruction. Am Rev Respir Dis 1992;146:104-8.

5 Samuelsson B. Leukotrienes: mediators of immediate hypersensitivity reactions and inflammation. Science 1983; 220:568-75.

6 Drazen JM, Austen FK, Lewis RA, et al. Comparative airway and vascular activity of leukotriene C-1 and D in vivo and in vitro. Proc Natl Acad Sci USA 1980;77:434558.

7 Marom ZVI, Shelhamer JH, Bach MK, et al. Slow-reacting substances, leukotriene $\mathrm{C} 4$ and D4 increase the release of mucus from human airways. Am Rev Respir Dis 1982;126: 449-51.

8 Barnes NC, Piper PJ, Costello JF. Comparative actions of inhaled leukotriene $\mathrm{C} 4$, leukotriene $\mathrm{D} 4$ and histamine in normal subjects. Thorax 1984;39:500-4

9 Knorr B, Matz J, Bernstein JA, et al, Montelukast for chronic asthma in 6 to 14 -year-old children: a randomized, double-blind trial. FAMA 1998;279:1181-6.

10 Reiss TF, Chervinsky P, Dockhorn RJ, et al. Montelukast, a once daily leukotriene receptor antagonist, in the treatment of chronic asthma. A multicenter, randomized, doubleblind trial. Arch Intern Med 1998;158:1213-20.

11 American Thoracic Society. Standardization of spirometry: 1994 update. Am f Respir Crit Care Med 1995;152:110736.

12 Cheng H, Leff JA, Amin R, et al. Pharmacokinetics, bioavailability, and safety of montelukast sodium (MK0476) in healthy males and females. Pharm Res 1996;13: 445-8.

13 Altman LC, Munk Z, Seltzer J, et al. A placebo-controlled, dose-ranging study of montelukast, a cysteinyl leukotrienereceptor antagonist. $\mathcal{F}$ Allergy Clin Immunol 1998;102:50-6.

14 Noonan MJ, Chervinsky P, Brandon M, et al. Montelukast, a potent leukotriene receptor antagonist, causes doserelated improvements in chronic asthma. Eur Respir $\mathcal{f}$ 1998;11:1232-9.

15 Bronsky EA, Kemp JP, Zhang J, et al. Dose-related protection of exercise bronchoconstrition by montelukast, a cysteinyl leukotriene-receptor antagonist, at the end of a once-daily dosing interval. Clin Pharmacol Ther 1997;62: 556-61.

16 Reiss TF, Sorkness CA, Stricker W, et al. Effects of montelukast (MK-0476), a potent cysteinyl leukotriene receptor antagonist, on bronchodilation in asthmatic subjects treated with and without inhaled corticosteroids. Thorax 1997;52:45-8.

17 Impens N, Reiss TF, Teahan JA, et al. Acute bronchodilation with an intravenously administered leukotriene D4 tion with an intravenously administered leukotriene D4 antagonist, MK-679. Am Rev Respir Dis 1993;147:1442-6.
18 Manning PJ, Watson RM, Margolskee DJ. Inhibition of Manning PJ, Watson RM, Margolskee DJ. Inhibition of
exercise-induced bronchoconstriction by MK-571, a poexercise-induced bronchoconstriction by $\mathrm{MK}-571$, a po-
tent leukotriene $\mathrm{D}_{4}$-receptor antagonist. $N$ Engl f Med tent leukotriene D

19 Gaddy JN, Margolskee DJ, Bush RK, et al. Bronchodilation with a potent and selective leukotriene $\mathrm{D} 4\left(\mathrm{LTD}_{4}\right)$ receptor antagonist (MK-0571) in patients with asthma. Am Rev Respir Dis 1992;146:358-63.

20 Hui KP, Barnes NC. Lung function improvement in asthma with a cysteinyl-leukotriene receptor antagonist. Lancet 1991;337:1062-3.

21 Reiss TF, Sorkness CA, Stricker W, et al. Effects of montelukast (MK-0476), a potent cysteinyl leukotriene receptor antagonist, on bronchodilation in asthmatic subjects treated with and without inhaled corticosteroids. Therax 1997;52:45-8.

22 McDermott MF, Murphy DG, Zalenski RJ, et al. A comparison between emergency diagnostic and treatment unit and inpatient care in the management of acute asthma. Anit and inpatient care in the managem

23 US Public Health Service. Healthy People 2000: National Promotion and Disease Prevention Objectives-Full Report. 
Washington, DC: US Dept of Health and Human Services PHS 91-50212, 1990: 1-692.

24 Strauss L, Hejal R, Galan G, et al. Observations on the effects of aerosolized albuterol in acute asthma. Am f Respir Crit Care Med 1997; 155:454-8.

25 FitzGerald JM, Grunfeld A, Pare PD, et al. The clinical efficacy of combination nebulized anticholinergic and adrenergic bronchodilators vs nebulized adrenergic bronchodilator alone in acute asthma. Canadian Combivent Study Group. Chest 1997;111:311-5.

$26 \mathrm{McFadden}$ ER, El Sandadi N, Strauss L, et al. The influence of parasympatholytics on the resolution of acute attacks of asthma. Am F Med 1997;102:7-13.
27 Fanta $\mathrm{CH}$, Rossing TH, McFadden ER. Emergency room treatment of asthma. Am $\mathcal{F}$ Med 1982;72:416-22.

28 Rossing TH, Fanta CH, McFadden ER, et al. A controlled trial of the use of single vs combined-drug therapy in the treatment of acute episodes of asthma. Am Rev Respir Dis 1981;123:190-4.

29 Tan KS, Grove A, McLean A, et al. Systemic corticosteroid rapidly reverses bronchodilator subsensitivity induced by formoterol in asthmatic patients. Am F Respir Crit Care Med 1997;156:28-35.

30 Lin RY, Pesola GR, Westfal RE, et al. Early parenteral corticosteroid administration in acute asthma. Am f Emerg 